\title{
Discussion of Review Article by Lee and Lin on Mini Gastric Bypass (One-Anastomosis Gastric Bypass) - OBES SURG DOI 10.1007/s11695-014-1369-9
}

\author{
Mervyn Deitel • Kuldeepak S. Kular • \\ Jean-Marc Chevallier
}

Published online: 3 September 2014

(C) Springer Science+Business Media New York 2014

To the Editor:

Drs. W-J Lee and Y-H Lin have written a good appraisal of the clinical value of mini gastric bypass (MGB) or oneanastomosis gastric bypass (OAGB), although their final recommendations on specific uses of this operation are contentious. However, their renaming of the operation to SAGB is bothersome. The operation commencing in 1997 and described over the years as MGB [1] and also described since 2004 as OAGB [2] would best not be tampered with. Indeed, in the authors' references, either the well-established names $M G B$ (as he used in his own many previous papers) and $O A G B$ are used throughout, as in the earlier part of their article. The many articles on this operation are found in PubMed under mini gastric bypass to this day [3] or oneanastomosis gastric bypass. A change in name will cause confusion, especially with the single-anastomosis duodenoileal (SADI-S) bypass of Torres' group [4], a modification of which Dr. Lee had also been performing [5].

The organizers of the IFSO 2014 Montreal Course had named it "MGB/OAGB", but Dr. Lee who was on the IFSO Scientific Planning Committee took it upon himself to rename the course "Single-Anastomosis Gastric Bypass," which led us to change our flyer and also has caused some confusion with those who were looking into the course.

\section{Deitel $(\bowtie)$ \\ International Bariatric Club, Toronto, Canada \\ e-mail: book@obesitysurgery.com}

\section{K. S. Kular}

Kular Medical and Research Society, Bija, India

e-mail: drkskular@gmail.com

J.-M. Chevallier

Hôpital Européen Georges Pompidou, Paris, France

e-mail: jean-marc.chevallier@egp.aphp.fr
There are many operations which we could rename more accurately (eg., sleeve gastrectomy in our papers), but this would cause confusion with the long-established recognized understood names.

Dr. Lee could have discussed his suggested name change with the attendees at the past MGB/OAGB Consensus meetings or the upcoming IFSO Montreal Course. The common name for this operation one-anastomosis gastric bypass has the identical meaning in English as single-anastomosis gastric bypass, so why duplicate this? To be clear, in a number of invited chapters that are now in press, we have been using MGB/OAGB in the title to be comprehensive and clear.

Conflict of Interest All three authors have approved the manuscript and have no conflict of interest.

Author Note Dr. Mervyn Deitel is Founding Editor and Editor-inChief Emeritus of Obesity Surgery. Professor Jean-Marc Chevalier is President de la SOFFCO in Paris, France.

\section{References}

1. Rutledge R. The mini-gastric bypass: experience with the first 1,274 cases. Obes Surg. 2001;11:276-80.

2. Garcia-Caballero M, Carbalo M. One anastomosis gastric bypass: a simple, safe and efficient procedure for treating morbid obesity. Nutr Hosp. 2004;19:372-5.

3. Georgiadou D, Sergentanis TN, Nixon A, et al. Efficacy and safety of laparoscopic mini gastric bypass. A systematic review. Surg Obes Relat Dis.2014;15. doi: 10.1016/j.soard.2014. 02.009 .

4. Sanchez-Pernaute A, Herrera MA, Perez-Aguirre ME, et al. Single anastomosis duodenoileal bypass with sleeve gastrectomy (SADI-S). One to three-year follow-up. Obes Surg. 2010;20:1720-6.

5. Lee WJ, Lee KT, Kasama K, et al. Laparoscopic single-anastomosis duodenal-jejunal bypass with sleeve gastrectomy (SADJB-SG): shortterm result and comparison with gastric bypass. Obes Surg. 2014;24: $109-13$. 